\title{
Missing Children Photograph Appeals: Does the Number of Appeals Affect Identification Accuracy Following a Short Recall Delay?
}

\author{
Daniel Hunt ${ }^{1}$ (D) $\cdot$ Maria loannou ${ }^{1} \cdot$ John Synnott ${ }^{1}$ \\ Published online: 26 June 2019 \\ (C) The Author(s) 2019
}

\begin{abstract}
The study objectives were (1) to determine if there were any associations between the time spent observing fictional appeals and identification accuracy, (2) to establish if the number of missing children photographs observed influences identification accuracy and (3) to determine whether the number of missing children appeals observed influences identification accuracy following a short 3-day delay. A two-stage approach was utilised. Two hundred and forty-two participants observed one, four or eight mock missing children photographs followed by a short word memory distraction task and a target present line-up identification task. The second stage comprised of another target present line-up identification task presented after a short 3-day delay. One-way between-group ANOVAs indicate that observing one missing child photograph has significantly greater overall identification accuracy and lower identification error than viewing four or eight photographs immediately after observing the appeal and following a 3-day delay. Additional analyses found that the identification accuracy was significantly higher immediately after observation compared with the identification accuracy following a 3-day delay. The findings demonstrate the necessity for improving missing children appeals. Due to the exploratory nature of the study, additional research is required to explore these factors further.
\end{abstract}

Keywords Child rescue alerts $\cdot$ Missing children $\cdot$ Missing persons $\cdot$ Publicity appeals $\cdot$ Recall accuracy

An estimated 340,000 missing persons incidents are created each year within the UK, equal to one report every 90 seconds (Missing People 2018; National Crime Agency [NCA] 2017). Of these, approximately $60 \%$ relates to missing children although this is likely to be a significant underestimation (Hayden and Shalev-Greene 2016; Hill et al. 2016; Kiepal et al. 2012; Shalev et al. 2009). A common approach in this situation is for the police, family, friends, and charities to release a photograph of the missing children through the media in the hope that the public can help identify and locate the missing child (Lampinen et al. 2009; Lampinen et al. 2012a; Sweeney and Lampinen 2012). The use of the media is a vital resource for the police as it allows the photograph of the missing child to be viewed by a limitless number of individuals in a very short period of time (Fyfe et al. 2014; Taylor et al. 2013).

Daniel Hunt

D.Hunt2@hud.ac.uk

1 Department of Psychology, University of Huddersfield, Queensgate, Huddersfield HD1 3DH, UK
However, despite its frequent daily usage and its importance in helping locate missing children, there is a limited understanding of how effective these appeals really are.

Releasing photograph appeals of missing children is not a novel approach, having been published across a variety of online and offline sources such as milk cartons, posters, television broadcasts and social media sites (Drivsholm et al. 2017). One of the most widely used and recognised methods of disseminating appeals, however, derives from rescue alerts such as the America Missing Broadcast Emergency Response (AMBER; Gier et al. 2012) and Child Rescue alerts (Lampinen and Moore 2016). Rescue alerts issue statewide public alerts of missing and abducted children who are at imminent risk of harm with the purpose of requesting help from the public to locate or provide information on the missing child (NCA 2014; U.S. Department of Justice 2015). Researchers have argued, however, that this approach is more of a crime control theatre than an essential tool due to its overuse in releasing appeals with over 200 AMBER alerts issued annually across America (Griffin and Miller 2008; Griffin et al. 2007). Theoretically, the overuse of missing children appeals may reduce their overall effectiveness in receiving valuable information because of habituation which is the 
reduction in responsiveness to stimuli that are identical and presented in a short period time (Griffin et al. 2007; Lampinen and Moore 2016). The ability of individuals to successfully identify others has also been found to be relatively poor (Davis and Valentine 2009).

\section{Facial Recognition and Frequency}

The effectiveness of missing children appeals relies in part on the successful identification of the child via facial recognition which is one of the most distinctive cues available used to determine the identity of an individual (Gier et al. 2017; Mian and Mondloch 2012). Although many can accurately identify faces they are familiar with (Burton et al. 1999), the majority of individuals are highly inaccurate with unfamiliar faces (Davis and Valentine 2009; Megreya and Burton 2006, 2008). In addition, research has also shown that the ability to store and recall information is influenced by the frequency of the items presented with more frequent observations producing greater accuracy than less frequent items (Loftus 1979).

Sweeney and Lampinen (2012) sought to explore the effect of frequency and facial recognition by analysing the identification accuracy of photographs from 96 student participants. All participants were randomly assigned to observe a mock missing child appeal that contained one image or a mock missing child appeal that contained three images of the same child (Sweeney and Lampinen 2012). After observation, participants engaged in a 50-image group sorting task that had included the target child (Sweeney and Lampinen 2012). They were instructed during the task to signify a child to the authorities using their keyboard if they came across the missing child (Sweeney and Lampinen 2012). The results found that the participants who observed three images of the same child had significantly greater identification accuracy than individuals who had observed the single image appeal (Sweeney and Lampinen 2012).

Although the study indicates greater frequency is associated with greater accuracy, this effect is only prevalent when the frequency of the images is of the same individual. For instance, Lampinen and Moore (2016) randomly assigned 465 American student participants either to observe three mock missing person appeals of different unfamiliar individuals across a 3-day duration or to observe one unfamiliar mock missing person appeal presented on the final day of the experiment (Lampinen and Moore 2016). The participants in both conditions were informed that the appeals were not real but if they happen to identify one of the individuals presented in the appeal throughout the university campus, they are required to inform the researchers (Lampinen and Moore 2016). The target individual who the participants were required to report to the researchers was shown in the mock appeal for the single appeal condition and in the final mock appeal within the 3-day duration condition (Lampinen and Moore 2016). All participants who correctly informed the researchers would win a share of $\$ 200$. The findings revealed that the participants who had observed just one appeal had significantly greater identification accuracy than individuals who had observed three appeals (Lampinen and Moore 2016).

Similarly, Lampinen et al. (2012b) randomly assigned 50 American university student participants to observe four mock missing children appeals or 12 mock missing children appeals displayed on a large board (Lampinen et al. 2012a, b). Participants were able to spend as much or as little time observing the appeals (Lampinen et al. 2012a, b). Following the observation of the appeals, participants engaged in a photograph team sorting task which presented a series of child photographs including the target photographs, foil and non-foil photographs (Lampinen et al. 2012a, b). Although the overall times spent observing the appeals were near identical across the two conditions, there was a significant difference when broken down into the time spent observing each individual photograph appeal. Those observing the four mock appeals spent a significantly greater time duration per appeal $(M=$ $12.93 \mathrm{~s}, S D=4.24)$ than the 12 mock appeals $(M=4.47 \mathrm{~s}$, $S D=1.66 ; t(48)=9.29, p=<.001, d=2.63$; Lampinen et al. 2012a, b). Moreover, participants observing the four mock appeals were found to have significantly greater identification accuracy than participants observing 12 mock appeals (Lampinen et al. 2012a, b).

It is not just students who perform badly at identifying faces as research has shown even those trained to recognise faces can perform poorly. White et al. (2014) analysed the accuracy of identifying unfamiliar faces by 30 passport officers via an active passport control centre. Thirty-four student participants were provided with an unknown genuine passport or a fraudulent passport which bore a photograph that shared similar features to the participant (White et al. 2014). The results indicated that the passport officers had incorrectly rejected $6 \%$ of the genuine passports and had wrongly accepted $14 \%$ of the fraudulent passports (White et al. 2014). This finding thus demonstrates the difficulty in identifying unfamiliar faces which is a frequent occurrence within missing children appeals.

\section{Time Duration}

Although the previous studies demonstrate how the effect of the frequency of targets required to be observed influences the subsequent identification accuracy, this may be associated with the amount of time available to the individual. Theoretically, as the time available to observe an item increases, the ability to encode the information present also increases (Kapardis 2014). Subsequently, the increased ability to encode information allows improved recall from long-term 
memory. Yarmey et al. (2002) demonstrate this effect with a confederate approaching members of the public and asking for directions. The interactions between the confederate and the participant lasted either for $5 \mathrm{~s}$ or for $30 \mathrm{~s}$ (Yarmey et al. 2002). Once the confederate had left, the researchers approached the members of the public and asked them to recall as much information as they could about the confederate (Yarmey et al. 2002). The results found that those who had engaged with the confederate for $30 \mathrm{~s}$ had significantly greater accuracy in recall than the individuals who had only engaged with the confederate for $5 \mathrm{~s}$ (Yarmey et al. 2002).

Similarly, Horry et al. (2014) analysed archival evidence of eyewitness reports across a variety of crimes to explore their accuracy in identifying the suspect. All eyewitness accounts were cross-referenced with video footage of the crime (Horry et al. 2014). The results indicated that the individuals who had been exposed to the crimes for a greater period had significantly greater identification accuracy than individuals who had been exposed to the crime for a shorter period (Horry et al. 2014). Hence, identification ability may be influenced by the time available to encode the information. In relation to missing children appeals, Lampinen et al. (2012b) argue that if an individual is only able, or willing, to give a limited amount of time to an item, then an increase in the amount of information required to be encoded would result in less time available per item. Thus, the ability to encode the information successfully would significantly reduce.

\section{Present Study}

Despite its importance and wide use, the research literature exploring the effectiveness of missing children appeals in recognising children is limited (Drivsholm et al. 2017; Lampinen and Moore 2016; Lampinen \& Sweeney, 2014). Moreover, it is suggested that individuals are generally quite poor at recognising unfamiliar faces (Davis and Valentine 2009; Megreya and Burton 2006, 2008), especially when their attention is elsewhere (Lampinen et al. 2012b; Miles 2005; Nobel and Shiffrin 2001). Therefore, the current study sought to fill this gap in our understanding by aiming to explore the effectiveness of missing children photograph appeals on the ability to accurately identify the child from a sequential lineup. The originality of this study is twofold. First, the study presents a novel insight into the exploration of how the number of missing children appeals influences the subsequent identification accuracy from members of the public in the UK during a target present line-up. Second, the study further explores how the number of appeals observed by members of the public affects their subsequent identification accuracy following a short 3-day delay.

The objectives of the current study are therefore to (1) determine whether there is an association between the length of time spent observing each individual photograph and the subsequent identification accuracy; (2) to establish whether the number of missing children photograph appeals observed in a short period of time influences the overall identification accuracy score immediately after observation; (3) to explore whether participant confidence is associated with overall identification accuracy; and (4) to determine whether the number of missing children photograph appeals observed initially influences the identification accuracy score from members of the public following a short 3-day delay.

\section{Method}

\section{Design}

The study adopted a mixed within-between-subject experimental design. The independent variables involved the number of photographs observed with three levels: one, four or eight photographs, and the level of confidence in identification accuracy ranged from 0 to $100 \%$. The dependent variable in the study comprised of the identification accuracy score which was calculated as the number of correct identifications made from a line-up of 29 photographs divided by the number of potential correct identifications. This figure was then multiplied by 100 to derive an identification accuracy percentage score. For instance, the one photograph condition had either $100 \%$ accuracy for identifying the target from a potential 29 images or $0 \%$ accuracy for failing to identify the target. In contrast, the eight-photograph condition had a potential of eight targets from 29 images and thus had a greater range of potential scores.

\section{Sample}

A total of 286 participants completed the study via convenience and snowball sampling methods, although 44 participants were removed from the final data due to misreading the free recall task or for only partially completing the full initial study. Thus, the final sample consisted of 242 participants (205 females; $M_{\text {age }}=23.32$ years, $S D=8.89$ ) who were included in the analysis for the initial study results. Of the final 242 participants, $81(33.50 \%)$ were randomly assigned to the 1-photograph condition, $81(33.50 \%)$ were randomly assigned to the 4-photograph condition and $80(33.00 \%)$ were randomly assigned to the 8-photograph condition.

Following the initial experimental study, a secondary follow-up experimental task was performed 3 days later. Of the potential 242 participants who had completed the initial experiment, 89 (36.78\%) participants had dropped out and did not complete the follow-up line-up task. Therefore, the final follow-up experiment sample comprised of 153 participants who were included for the delayed study results. The participant conditions for the delayed task comprised of $49(32.02 \%)$ 
within the 1-photograph condition, $50(32.68 \%)$ within the 4photograph condition and $54(35.29 \%)$ within the 8photograph condition.

All research participants were recruited via an online experimental recruitment system at the university and had received 0.5 credits for taking part. Participants were also recruited voluntarily via social media sites and did not receive any incentives for taking part. The participants were able to participate in the experimental studies at any time and in any location that they found most comfortable. The study was accessed via their home computer or mobile device using the Qualtrics software. Full ethical approval was granted by the School Research Ethics Panel at the university. Table 1 presents the demographic background statistics for the sample.

\section{Materials}

Participants completed one initial online experimental study and one follow-up online experimental study which comprised the following.

\section{Fictional Photographs}

The participants were randomly assigned to one of three fictional photograph appeals of a missing child: one photograph, four photographs and eight photographs. Participants in the 1photograph condition had to observe the fictional missing child image for $15 \mathrm{~s}$ due to previous research, suggesting that the average time required to observe a photograph was $13 \mathrm{~s}$ (Lampinen et al. 2012a, b). The remaining two conditions did not have a set time but were timed in the background to identify how long each participant spent observing the individual photographs. The target photograph presented within the onephotograph condition was also one of the target photographs presented within the four- and eight-photograph conditions. Likewise, all four photographs in the four-photograph condition were presented as four of the eight target photographs in the eight-photograph condition.

\section{Memory Distraction Task}

Participants were asked to complete a very short memory task in which they would be unable to go back to the previous task or forward to the next task for the duration of the distraction task. This task was included in the study to minimise the rehearsal of the images presented by the participants. All participants were presented with five individual tables consisting of five rows and two columns. Within the table, ten single and randomised nouns were contained which had been generated from an online random word generator (www.randomlists. com/nouns). Each of the five ten-word tables was displayed for $20 \mathrm{~s}$ and presented within a sequential order. The distraction task, therefore, totalled 50 words being presented in $100 \mathrm{~s}$.
Table 1 Demographic factors of ethnicity, education, employment and marital status for the final sample

\begin{tabular}{|c|c|c|}
\hline Demographic variable & Number & Percent \\
\hline \multicolumn{3}{|l|}{ Ethnicity } \\
\hline White British & 145 & 59.90 \\
\hline White other & 16 & 6.60 \\
\hline Black & 12 & 5.00 \\
\hline Asian & 51 & 21.10 \\
\hline Chinese, Japanese or Southern Asian & 2 & 0.80 \\
\hline Middle Eastern & 5 & 2.10 \\
\hline Other & 11 & 4.50 \\
\hline \multicolumn{3}{|l|}{ Highest level of education completed } \\
\hline No schooling completed & 1 & 0.40 \\
\hline Primary & 2 & 0.80 \\
\hline Secondary & 5 & 2.10 \\
\hline College/sixth form & 176 & 72.70 \\
\hline Trade, technical or vocational & 11 & 4.50 \\
\hline Associate degree & 10 & 4.10 \\
\hline Bachelor's degree & 29 & 12.00 \\
\hline Master's degree & 4 & 1.70 \\
\hline Doctorate degree & 3 & 1.20 \\
\hline Other & 1 & 0.40 \\
\hline \multicolumn{3}{|l|}{ Current employment status } \\
\hline Full time & 9 & 3.70 \\
\hline Part time & 84 & 34.70 \\
\hline Unemployed & 8 & 3.30 \\
\hline Retired & 3 & 1.20 \\
\hline Student & 195 & 80.60 \\
\hline Unable & 6 & 2.50 \\
\hline Other & 2 & 0.80 \\
\hline \multicolumn{3}{|l|}{ Marital status } \\
\hline Single & 215 & 88.80 \\
\hline Married & 21 & 8.70 \\
\hline Divorced & 1 & 0.40 \\
\hline Separated & 1 & 0.40 \\
\hline Other & 4 & 1.70 \\
\hline
\end{tabular}

The cumulative percentages may be above $100 \%$ due to participants having the option to select more than one response

Participants were asked to 'try and remember as many of the words that will be displayed as possible as this may be tested later in the study'. The participants were not informed of this task prior to the task.

\section{Line-up Task}

The line-up task was identical for all the participants regardless of their experimental condition. The line-up comprised of 29 photographs of children presented in a randomised and sequential order for each participant regardless of their experimental condition. The images 
within the line-up task included all eight target photographs, foil images and non-foil images. Target photographs were either presented as the same image participants had observed or an alternative image previously unseen but of the same child in the mock appeal (see Fig. 1 for examples). When the participants were presented with an image, they were asked whether the child was one of the missing children in the appeal that they had originally observed and could respond through a dichotomous yesno response. Participants were also requested to indicate their level of confidence in their own accuracy from a slidable scale that ranged from $0 \%$ confident to $100 \%$ confident.

\section{Demographic Survey}

The demographic survey section requested participants to specify their age, gender, ethnic background, the highest level of education completed, their current employment status and their current marital status. All the responses allowed participants to select one of the predetermined responses excluding age which was open-ended.

\section{Delayed Line-up Task}

The delayed line-up task was identical to the initial experiment line-up task detailed above. The only exception to this was that each image was again presented in a random and sequential order so it would not appear in the same order as initially observed. Participants were presented with an image and asked whether the child was one of the missing children in the appeal that they had originally observed and could respond through a dichotomous yes-no response. Participants were also requested to indicate their level of confidence in their own accuracy from a slidable scale that ranged from $0 \%$ confident to $100 \%$ confident.

\section{Procedure}

The study was performed using the Qualtrics Inc. survey software (www.Qualtrics.com). Participants observing the social media posting or via the study details within the university's online experimental recruitment system were requested to select the web link if they wished to participate. Participants were then presented with an information sheet that detailed the experiment purpose, collection of data, storage of the data, ethical considerations and contact details of the researcher followed by a consent form. All the participants were randomly assigned via the Qualtrics system to one of the three available experimental conditions. Participants were presented with either one photograph, four photographs or eight photographs, and asked to simply observe the mock appeal. Participants in the 4-photograph and 8-photograph conditions were also told that they could spend as much or as little time as they wished to observe the appeal.

After completing the observational task, all participants were presented with a short distraction task to minimise the rehearsal of the photographs. Participants were requested to try to memorise as many of the words that will be presented as possible. The final segment of the experiment presented participants with the same identical line-up task that enclosed a total of 29 images of children and who were asked to indicate whether they believe this child was or was not the same child presented in one of the mock appeals they had observed previously. The participants were also requested to indicate their level of confidence in their identification accuracy from a scale of 0 to $100 \%$ confident for each image (Fig. 2). The initial experiment ended with details of the delayed task, a request for an email address to participate in the delayed task and a full debrief.

After a short 3-day break, all participants who had provided an email address were emailed to thank them again for participating in the first experiment and were presented with details of the follow-up task with a unique Web link. The unique Web link was generated by the Qualtrics software to allow data
Fig. 1 Example of the target (a), alternative (b), foil (c) and nonfoil (d) photographs used in lineup task

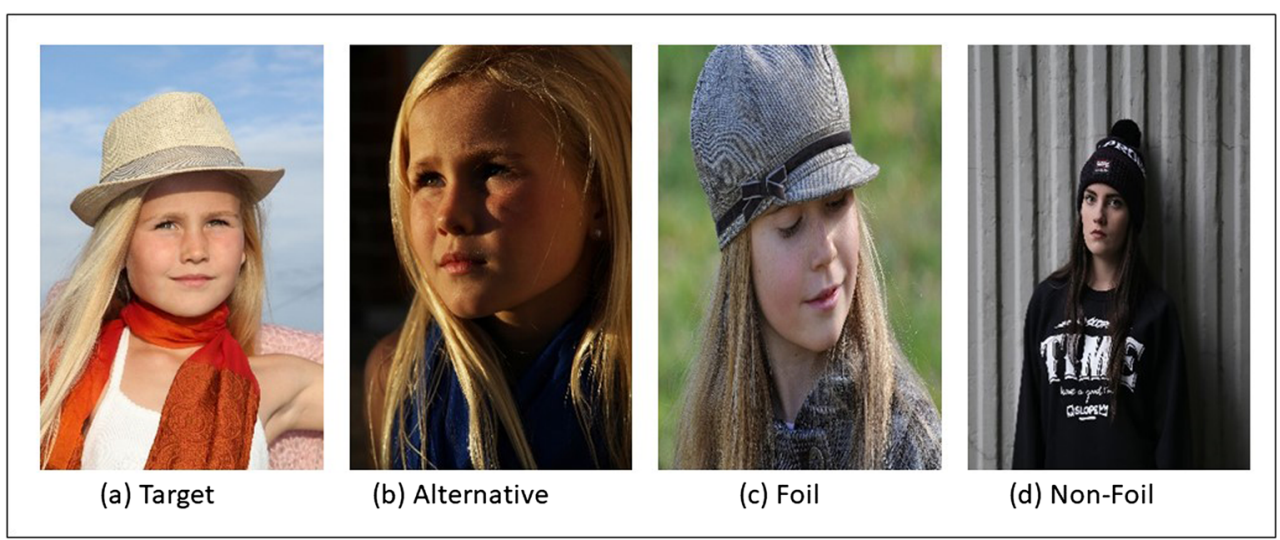




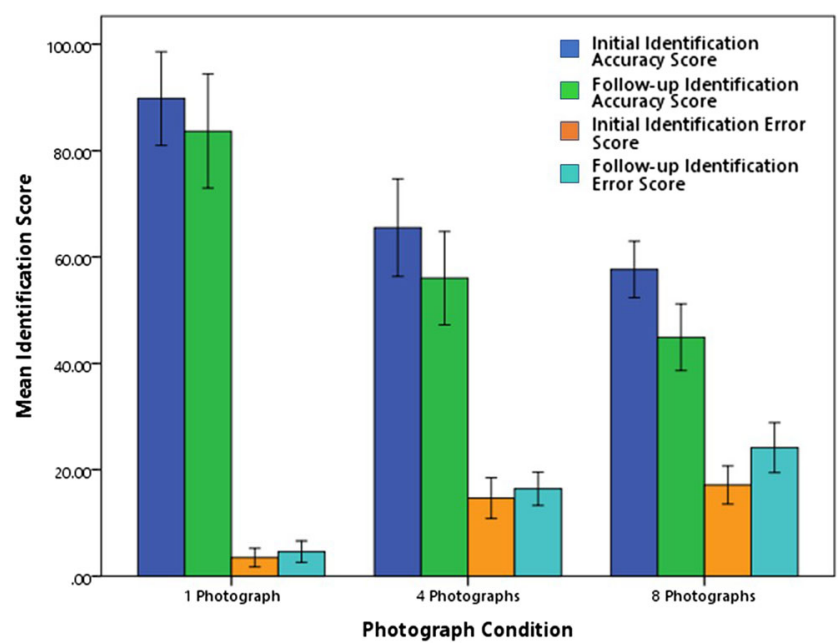

Fig. 2 Initial identification accuracy and identification error and identification accuracy and identification error following a 3-day break across the three experimental condition groups

from participants to be matched with their initial experimental data. Following the Web link, the participants were directed to a brief information page detailing the task. The same line-up task presented in the initial experiment was presented again to the participants, albeit in a randomised order. Participants were once again requested to indicate whether the child displayed was or was not the same child presented within the mock appeal that they had initially observed 3 days previously. They were also requested to indicate their level of confidence in their identification from a scale of 0 to $100 \%$ confident. The delayed task concluded with a full debrief and thanking their participation.

\section{Analysis}

All data across the two experimental studies were input manually by the researcher to SPSS version 24 for analysis. Identification accuracy scores were calculated by summing the number of correct identifications made during the lineup task and dividing this total by the maximum number of potential correct identifications. For instance, the fourphotograph condition had a maximum potential of correctly identifying four target images from 29 within the line-up. Similarly, identification error scores were calculated by summing the number of incorrect identifications made during the line-up task and dividing this total by the maximum number of potential incorrect identifications: for example, in participants who had incorrectly indicated that a nontarget photograph was the missing child, this would contribute to their overall recall error score. These final figures were then multiplied by 100 to derive an identification accuracy or identification error percentage score. A majority of variables subject to quantitative analysis were in a dichotomous format with $0=$ no and $1=$ yes.

\section{Results}

\section{Initial Experimental Task}

\section{Time Duration}

The first objective of the study was to explore the associations between the length of time spent observing the target photographs of the missing children and the overall identification accuracy. For the 1-photograph condition, all participants observed the image for $15 \mathrm{~s}$ and, thus, no variation in time is present. This time duration was used as the baseline for the remaining photograph conditions. For participants within the 4-photograph condition, Spearman's rho correlations found significant associations for the relationships between the time spent observing the photographs of the missing children and identification accuracy for the images of target $1\left(r_{s}=.375, n=81, p=0.001\right)$, target 2 $\left(r_{s}=.372, n=81, p=0.001\right)$, target $3\left(r_{s}=.398, n=81, p=<\right.$ $0.001)$ and target $4\left(r_{s}=.375, n=81, p=0.001\right)$.

Finally, Spearman's rho correlations found mixed associations for the relationship between the time spent observing the photographs of missing children in the 8-photograph condition and identification accuracy. Significant associations were found for target $6\left(r_{s}=.257, n=80, p=0.021\right)$ and target 7 $\left(r_{s}=.272, n=80, p=0.015\right)$. In contrast, non-significant associations were found for target $1\left(r_{s}=.116, n=80, p=\right.$ $0.308)$, target $2\left(r_{s}=.191, n=80, p=0.090\right)$, target $3\left(r_{s-}\right.$ $=.147, n=80, p=0.194)$, target $4\left(r_{s}=.160, n=80, p=\right.$ $0.157)$, target $5\left(r_{s}=.210, n=80, p=0.061\right)$ and target $8(r-$ $\left.{ }_{s}=.181, n=80, p=0.107\right)$. The mean times spent observing the photographs are displayed in Table 2.

\section{Frequency of Photographs}

The second objective was to establish if the number of missing children photograph appeals observed by participants in a short period of time influences the overall identification accuracy score immediately after observation. The one-way betweengroup ANOVA found a significant and small effect for the number of photographs observed and overall identification accuracy $\left(f(2239)=42.02, p=<0.001, \omega^{2}=0.50\right)$. Post hoc analysis via Tukey Honest Significant Difference (HSD) indicated a significant difference in mean identification accuracy when observing one photograph $(M=91.36, S D=28.27)$ compared with observing four photographs $(M=65.12, S D=27.58)$ and eight photographs $(M=56.25, S D=18.87)$. There were no significant differences in mean identification accuracy scores between observing four photographs and eight photographs. Hence, higher identification accuracy is significantly associated with observing fewer images of missing children.

In relation to identification error, the one-way betweengroup ANOVA indicated a significant and small effect for the number of target photographs observed $(f(2241)=33.37$, 


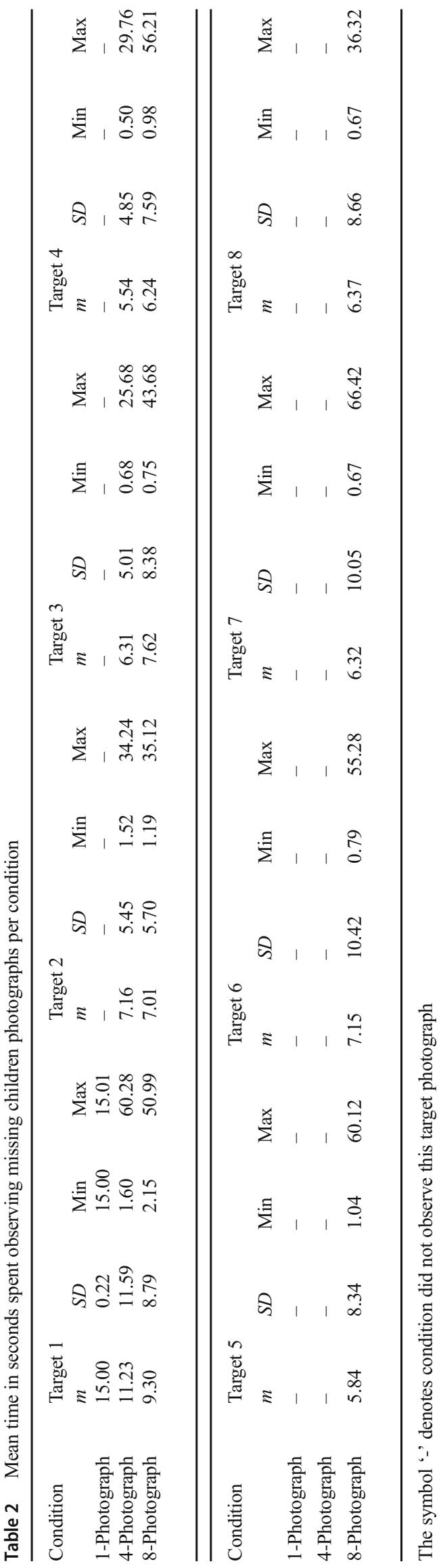

$p=<0.001, \omega^{2}=0.46$ ). Post hoc analysis via Tukey HSD indicated that there was a significant difference in mean identification error with a lower error score for individuals observing one photograph $(M=3.67, S D=6.50)$ compared to observing four photographs $(M=13.88, S D=12.20)$ or eight photographs $(M=16.73, S D=12.29)$. There were no significant differences in mean identification error between observing four photographs and eight photographs. Thus, higher identification errors are associated with observing a higher number of target missing children photographs.

\section{Confidence}

The third research objective sought to explore whether participant confidence influenced the overall accuracy in identification between the three experimental conditions. All participants had observed target photograph 1 . The full model of the binary logistic regression containing all predictors was significantly significant $\left(x^{2}(3, n=242)=22.91, p=<0.001\right)$, correctly classified $74.80 \%$ of cases and explained between 9\% (Cox and Snell $R^{2}$ ) and 13\% (Nagelkerke $R^{2}$ ) of the variance in identification accuracy. The experimental condition was the only variable that made a significant contribution to the model. Recall accuracy scores were significantly lower for participants who observed four photographs $(\mathrm{OR}=0.23)$ and for participants who observed eight photographs $(\mathrm{OR}=0.14)$ when compared with just one photograph being presented. There was no significant association between participants' level of confidence in the accuracy of target photograph one and overall recall accuracy.

To explore the associations between participant confidence and overall recall accuracy for the remaining target photographs, a series of Spearman's rho correlations were performed. The results found mixed associations between participant level of confidence and overall identification accuracy. There was a significant and positive association for target 2 $\left(r_{s}=.34, n=161, p=<0.001\right)$ and target $8\left(r_{s}=.37, n=80\right.$, $p=0.001)$. Significant and negative associations were also found for target $4\left(r_{s}=-.49, n=161, p=<0.001\right)$, target $5(r$ $\left.{ }_{s}=-.22, n=80, p=0.047\right)$ and target $7\left(r_{s}=-.31, n=80\right.$, $p=0.006)$. However, no significant associations between confidence level and overall identification accuracy were found for target $3\left(r_{s}=-.12, n=161, p=0.14\right)$ or target $6\left(r_{s}=.13\right.$, $n=80, p=0.261)$.

\section{Delayed Experimental Task}

\section{Time Duration}

The final objective of the study was to determine if there are any associations between the length of time spent observing the target photographs of missing children and the overall identification accuracy following a 3-day delay. Participants 
in the one-photograph condition observed the photograph for $15 \mathrm{~s}$ and were thus used as a baseline for comparison as no variability in time is present. For participants in the 4photograph condition, Spearman's rho correlations found significant relationships between the time spent observing the target photographs and identification accuracy following a short 3-day delay for target $1\left(r_{s}=.517, n=50, p=<0.001\right)$, target $2\left(r_{s}=.526, n=50, p=<0.001\right)$, target $3\left(r_{s}=.470, n=\right.$ $50, p=0.001)$ and target $4\left(r_{s}=.475, n=50, p=<0.001\right)$.

For participants within the eight-photograph condition, Spearman's rho correlations also found significant associations between the length of time spent observing the appeal and the overall identification accuracy for target $1\left(r_{s}=.312, n=54, p=\right.$ $0.022)$, target $2\left(r_{s}=.319, n=54, p=0.019\right)$, target $4\left(r_{s}=.364\right.$, $n=54, p=0.007)$, target $5\left(r_{s}=.363, n=54, p=0.007\right)$, target 6 $\left(r_{s}=.433, n=54, p=0.001\right)$ and target $7\left(r_{s}=.268, n=54, p=\right.$ $0.050)$. In contrast, there were no significant associations for target $3\left(r_{s}=.236, n=54, p=0.086\right)$ or target $8\left(r_{s}=.242, n=\right.$ $54, p=0.078)$. The results indicate that a majority of identification accuracy scores are positively associated with an increase in the time spent observing the original appeals.

\section{Frequency of Photographs}

A one-way between-group ANOVA was performed to explore the associations between identification accuracy following a 3 -day delay and the number of photographs observed finding a significant and small effect $(f(2152)=21.42, p=<0.001$, $\omega^{2}=0.46$ ). Post hoc analysis via Tukey HSD indicates a significant difference in mean follow-up identification accuracy when observing one photograph $(M=83.67, S D=37.34)$ compared with observing four photographs $(M=56.00$, $S D=30.95)$ or eight photographs $(M=44.91, S D=22.85)$. There were no significant differences between observing four photographs or eight photographs. Therefore, the results indicate that higher identification accuracy scores following a 3day delay are associated with an increase in the time spent observing the original appeals.

Additional analysis via a one-way between-group ANOVA indicated a significant and small effect for the number of target photographs observed initially and the overall identification error $\left(f(2152)=30.96, p=<0.001, \omega^{2}=0.53\right)$. Post hoc analysis via Tukey HSD found a significant difference in mean identification error with a lower error score for individuals observing one photograph $(M=4.59, S D=6.92)$ compared to observing four photographs $(M=16.40, S D=11.03)$ or eight photographs $(M=$ $24.16, S D=17.25)$. There was also a significant difference between identification error scores during the follow-up delayed task for observing four photographs $(M=16.40, S D=11.03)$ and eight photographs $(M=24.16, S D=17.25)$. The results demonstrate that higher follow-up identification error scores are significantly associated with an increase in the number of missing children photographs required to be observed.
Finally, a series of Wilcoxon signed-rank tests were performed to establish whether there were any differences between the initial and delayed identification accuracy scores. Finding a non-significant difference when observing just one missing child photograph $(T=3.00, p=0.180, r=-0.14)$. In contrast, the Wilcoxon signed-rank tests found significant differences for individuals who observed four photographs with higher initial identification accuracy scores $(M d n=75.00)$ than the delayed identification accuracy scores $(M d n=$ 62.50), $T=59, p=0.025, r=-0.22$ ). Likewise, a significant difference for individuals observing eight photographs was also found with higher initial identification accuracy scores $(M d n=62.50)$ than delayed identification accuracy scores $(M d n=50.00 ; T=199.50, p=<0.001, r=-0.38)$. Therefore, the results suggest that as the duration between observing a missing child and the necessity of being able to correctly identify and recognise them increases, their identification accuracy scores will significantly decrease.

\section{Confidence}

The study further sought to explore whether participant confidence influenced the overall accuracy in identification between the three experimental conditions following a 3-day delay. As discussed previously, all participants had observed target photograph 1 ; therefore, a binary logistic regression was performed. The full model containing all predictors was significantly significant $\left(x^{2}(3, N=153)=16.51, p=0.001\right)$. The model correctly classified $72.50 \%$ of cases and explained between $10.20 \%$ (Cox and Snell $R^{2}$ ) and $14.30 \%$ (Nagelkerke $R^{2}$ ) of the variance in delayed identification accuracy. The experimental condition and participant confidence in identification accuracy made significant contributions to the model. Delayed identification accuracy scores were significantly higher for the participants who indicated higher levels of confidence $(\mathrm{OR}=1.02)$. Delayed identification scores were also significantly higher for participants who had observed one photograph compared with participants who observed eight photographs $(\mathrm{OR}=0.29)$, although there were no significant effects for participants who observed one photograph compared with participants who observed eight photographs (0.44).

To explore the associations between participant confidence and overall recall accuracy for the remaining target photographs, a series of Spearman's rho correlations were performed. Similar to the results of the initial study, the results for the delayed study also found mixed associations between participant level of confidence and overall identification accuracy. The results found a significant and positive association between confidence level and overall identification accuracy for target $6\left(r_{s}=0.0289, n=54, p=0.034\right)$. However, no significant associations between confidence level and overall identification accuracy were found for target $2\left(r_{s}=0.15\right.$, $n=104, p=0.121)$, target $3\left(r_{s}=-0.043, n=104, p=\right.$ 
$0.666)$, target $4\left(r_{s}=0.038, n=104, p=0.700\right)$, target $5\left(r_{s}=\right.$ $0.042, n=54, p=0.761)$, target $7\left(r_{s}=-0.147, n=54, p=\right.$ $0.288)$ or target $8\left(r_{s}=0.200, n=54, p=0.147\right)$.

\section{Discussion}

The aim of the present study was to explore the effectiveness of missing children photograph appeals on the ability to accurately identify the missing children during a line-up task. Specifically, the study sought to determine whether the number of missing children photograph appeals presented in a short period of time influences the subsequent identification accuracy of that child immediately after observing the photograph and again after a 3-day delay. The overall results suggest that the number of appeals observed does significantly influence the accuracy of identifying a missing child. Moreover, identification accuracy significantly decreases as the time between observation of the photograph and identification of the child increases when participants observe four- or eight-photograph appeals.

\section{Influence of Time Spent Observing the Photographs}

The results indicate that the amount of time spent observing a missing child photograph appeal did have a significant effect on the subsequent identification accuracy. Specifically, longer time durations spent observing the appeals were significantly associated with higher identification accuracy during the lineup task for the majority of the photographs observed with some mixed results found within the 8-photograph condition. The effect of time on subsequent identification accuracy can be explained by the ability to maximise full encoding of the observed information from short-term to long-term memory and thus further improving recall ability from long-term memory during the line-up identification task (Kapardis 2014).

This finding is supportive of the work by Yarmey et al. (2002) who found that convenience members of the public who had observed and interacted with a confederate target asking for directions for $30 \mathrm{~s}$ had superior identification recall accuracy than individuals who had only observed and interacted with the confederate target for $5 \mathrm{~s}$. Moreover, Horry et al.'s (2014) archival analysis of eyewitness statements further supports the current findings as they found that individuals who had greater exposure of the crimes had significantly greater offender suspect identification rates than the individuals who had a shorter exposure to the crimes.

\section{Influence of the Number of Appeals}

The results had further identified that the number of photographs of missing children required to be observed in a short period of time significantly influences identification accuracy.
Participants who had observed just one missing child photograph had significantly greater identification accuracy and lower identification error compared with individuals who had observed four or eight missing children photographs. This finding, therefore, supports the work by Lampinen and Moore (2016) who analysed the identification recall abilities of 465 participants following the observation of one or three mock missing persons appeals. Participants who had observed just one missing persons appeal on the final day of a 3-day event had a significantly greater number of correct sightings than participants who had observed three different missing persons appeals across the same 3-day period (Lampinen and Moore 2016).

This finding is of great significance as missing children appeals are an everyday common occurrence. Moreover, with an estimated 200 AMBER alerts released annually (Griffin and Miller 2008; Griffin et al. 2007) and the effect of habituation to identical stimuli (Rankin et al. 2009), the current findings suggest that the current and frequent use of missing children appeals may have a negative effect on the ability to help locate the missing child. In addition, if members of the public only have a limited amount of time available to provide to appeals, or are willing to provide, then the increase in the number of appeals required to be observed results in a decrease in the amount of time available to spend per appeal (Lampinen et al. 2012b). Hence, in relation to the first research finding, a decrease in the time available to encode the information within the appeal and an increase in the number of appeals required to be observed will significantly decrease the ability for individuals to be able to identify the missing child.

\section{Influence of Delay}

Finally, the results also discovered that the identification accuracy of missing children appeals significantly decreases as the time between observing the appeal and requiring to identify the missing child increases when observing four or eight photographs. Although not related to missing children photographs, the current findings are partly supported by Cary and Reder (2003) who analysed the recognition accuracy of lists of words from participants. All participants had observed a list of words of nouns that varied in length from 16 words to 64 words followed by a short distraction task (Cary and Reder 2003). Regardless of the number of words required to be recalled, all participants had significantly greater recognition accuracy prior to the delay than they did following the delay (Cary and Reder 2003). Despite this study exploring recollection of words and not faces, it demonstrates the effect that a delay has on the subsequent recall ability. Additional research would thus do well to explore this further as our current understanding is limited. 


\section{Limitations and Future Directions}

The study presents a relatively novel insight and builds on the limited literature exploring the effectiveness of missing children photograph appeals. As such, there are some limitations which must be considered. First, the study aimed to achieve a representative sample for the UK population which, although the clear majority of participants were female, had a white ethnic background and were students at the time of the experiment. Thus, future research should seek to develop a more representative sample to explore missing children appeal effectiveness to explore whether the background characteristics of the individual influences their ability to identify a missing child. For instance, gender and age have long been associated with differences in recall ability (Kapardis 2014). Nevertheless, the current sample did live within varied geographical locations across the UK to minimise the effect of location on identification ability.

Second, the photographs used within the experiment were fictional which may have contributed to the results. For instance, one image of a child may be more recognisable than another image of another child. Hence, future research could utilise previous and genuine missing children photographs to determine whether the type of images used also influences identification accuracy. Finally, the study utilised a short distraction task between observing the photographs and the lineup task in the form of a short 2-min memory retrieval method. The distraction task may not have fully prevented participants from rehearsing the images they had just observed. Future research could include a longer and more cognitive demanding distraction task to fully explore this effect further.

\section{Conclusion}

To sum up, the current study suggests that an increase in the number of missing children appeals required to be observed significantly reduces the identification accuracy during a lineup task. The results also demonstrated that as the length of time between observing the missing child and requiring to identify them increases, their identification accuracy significantly decreases when observing four or eight photographs. These findings present significant implications for the current method of disseminating and presenting missing children appeals. As the number of missing children appeals disseminated daily increase, the amount of time available to give to each appeal by members of the public decreases. Subsequently, this effect will significantly reduce the likelihood of members of the public being able to accurately identify the missing child.

This study is exploratory and therefore provides the foundations for additional research to build on these findings further. Additional research could, therefore, improve our understanding of the effectiveness of missing children appeals to identify the factors that are associated with improving or reducing the ability to locate and identify a missing child. These research findings are by no means an argument to reduce the use of media appeals to try and locate missing children but to identify the limitations in releasing missing appeals freely and frequently. There is a great need to explore and utilise the balance between the number of appeals being presented to the public in a more strategic manner and their ability to improve identification accuracy.

\section{Compliance with Ethical Standards}

Full ethical approval was granted by the School Research Ethics Panel at the university.

Conflict of Interest The authors declare that they have no conflict of interest.

Ethical Approval All procedures performed within the study that involved human participants were in accordance with the ethical standards of the University of Huddersfield (SREP/2017/095) and with the ethical standards of the British Psychological Society Code of Ethics and Conduct (2018).

Informed Consent Informed consent was obtained from all individual participants included in the study.

Open Access This article is distributed under the terms of the Creative Commons Attribution 4.0 International License (http:// creativecommons.org/licenses/by/4.0/), which permits unrestricted use, distribution, and reproduction in any medium, provided you give appropriate credit to the original author(s) and the source, provide a link to the Creative Commons license, and indicate if changes were made.

\section{References}

Burton M, Wilson S, Cowan M, Bruce V (1999) Face recognition in poor-quality video: evidence from security surveillance. Psychol Sci 10(3):243-248. https://doi.org/10.1111/1467-9280.00144

Cary M, Reder LM (2003) A dual-process account of the list-length and strength-based mirror effects in recognition. J Mem Lang 49(2): 231-248. https://doi.org/10.1016/s0749-596x(03)00061-5

Davis JP, Valentine T (2009) CCTV on trial: matching video images with the defendant in the dock. Appl Cogn Psychol 23(4):482-505. https://doi.org/10.1002/acp.1490

Drivsholm M, Moralis D, Shalev-Greene K, Woolnough P (2017) Once missing never forgotten? Results of scoping research on the impact of publicity appeals in missing children cases. Retrieved from: https://researchportal.port.ac.uk/portal/files/7514950/Once Missing_Never_Forgotten_final.pdf

Fyfe NR, Stevenson O, Woolnough P (2014) Missing persons: the processes and challenges of police investigation. POLIC SOC 25:1-17. https://doi.org/10.1080/10439463.2014.881812

Gier VS, Kreiner DS, Hudnell WJ (2012) AMBER alerts: are school-type photographs the best choice for identifying missing children? J Police Crim Psychol 27(1):9-23. https://doi.org/10.1007/s11896011-9085-z 
Gier VS, Kreiner DS, Lampinen JM (2017) Factors affecting recognition of senior citizens in a silver alert. J Police Crim Psychol 32(3):185196. https://doi.org/10.1007/s11896-016-9210-0

Griffin T, Miller MK (2008) Child abduction, AMBER alert, and crime control theatre. Crim Justice Rev 33(2):159-176. https://doi.org/10. 1177/0734016808316778

Griffin T, Miller MK, Hoppe J, Rebideaux A, Hammack R (2007) A preliminary examination of AMBER alert's effects. Crim Justice Policy Rev 18(4):378-394. https://doi.org/10.1177/0887403407302332

Hayden C, Shalev-Greene KS (2016) The blue light social services? Responding to repeat reports to the police of people missing from institutional locations. Polic Soc 28:1-17. https://doi.org/10.1080/ 10439463.2016.1138475

Hill L, Taylor J, Richards F, Reddington S (2016) 'No-one runs away for no reason': understanding safeguarding issues when children and young people go missing from home. Child Abuse Rev 25(3): 192-204. https://doi.org/10.1002/car.2322

Horry R, Halford P, Brewer N, Milne R, Bull R (2014) Archival analyses of eyewitness identification test outcomes: what can they tell us about eyewitness memory? Law Hum Behav 38(1):94-108. https://doi.org/10.1037/lhb0000060

Kapardis A (2014) Psychology and law: a critical introduction, 4th edn. Cambridge University Press, New York

Kiepal L, Carrington PJ, Dawson M (2012) Missing persons and social exclusion. Can J Sociol 37(2):137-168 Retrieved from: https:// ejournals.library.ualberta.ca/index.php.CJS/article/viewFile/10114/ 14107

Lampinen JM, Moore KN (2016) Missing person alerts: does repeated exposure decrease their effectiveness? J Exp Criminol 12(4):587598. https://doi.org/10.1007/s11292-016-9263-1

Lampinen, J. M., \& Sweeney, L. N. (2014). Associated adults: prospective person memory for family abducted children. Journal of Police and Criminal Psychology, 29(1), 22-27. doi: 10.1007/s11896-0139120-3

Lampinen JM, Arnal JD, Hicks JL (2009) The effectiveness of supermarket posters in helping to find missing children. J INTERPERS VIOLENCE 24(3):406-423. https://doi.org/10.1177/ 0886260508317184

Lampinen JM, Miller JT, Dehon H (2012a) Depicting the missing: prospective and retrospective person memory for age progressed images. Appl Cogn Psychol 26(2):167-173. https://doi.org/10.1002/ acp. 1819

Lampinen JM, Peters CS, Gier VS (2012b) Power in numbers: the effect of target set size on prospective person memory in an analog missing child scenario. Appl Cogn Psychol 26(5):702-708. https://doi.org/ 10.1002/acp. 2848

Loftus EF (1979) The malleability of human memory: information introduced after we view an incident can transform memory. Am Sci 67(3):312-320 Retrieved from: http://www.jstor.org/stable/ 27849223

Megreya AM, Burton AM (2006) Unfamiliar faces are not faces: evidence from a matching task. Mem Cogn 34(4):865-876. https:// doi.org/10.3758/BF03193433
Megreya AM, Burton AM (2008) Matching faces to photographs: poor performance in eyewitness memory (without the memory). J Exp Psychol Appl 14(4):364-372. https://doi.org/10.1037/a0013464

Mian JF, Mondloch CJ (2012) Recognizing identity in the face of change: the development of an expression-independent representation of facial identity. J Vis 12(7):1-11. https://doi.org/10.1167/12.7.17

Miles TJ (2005) Estimating the effect of America's Most Wanted: a duration analysis of wanted fugitives. J Law Econ 48(1):281-306. https://doi.org/10.1086/428718

Missing People (2018) Key information. Retrieved from: https://www. missingpeople.org.uk/about-us/about-the-issue/research/76keyinformation $2 . \mathrm{html}$

National Crime Agency [NCA] (2014) New alert system for missing children in danger. Retrieved from: http://www. nationalcrimeagency.gov.uk/news/368-new-alert-system-formissing-children-in-danger

National Crime Agency [NCA] (2017) Missing persons data report 2015/2016. Retrieved from: http://missingpersons.police.uk/en-gb/ resources/downloads/download/61

Nobel PA, Shiffrin RM (2001) Retrieval processes in recognition and cued recall. J Exp Psychol Learn Mem Cogn 27(2):384-413. https://doi.org/10.1037//0278-7393.27.2.384

Rankin CH, Abrams T, Barry RJ, Bhatnagar S, Clayton DF, Colombo J, Coppola G, Geyer MA, Glanzman DL, Marsland S, McSweeney FK, Wilson DA, Wu C, Thompson RF (2009) Habituation revisited: an updated and revised description of the behavioral characteristics of habituation. Neurobiol Learn Mem 92(2):135-138. https://doi. org/10.1016/j.nlm.2008.09.012

Shalev K, Schaefer M, Morgan A (2009) Investigating missing person cases: how can we learn where they go or how far they travel? Int J Police Sci Manag 11(2):123-116. https://doi.org/10.1350/ijps.2009. 11.2.116

Sweeney LN, Lampinen JM (2012) The effect of presenting multiple images on prospective and retrospective person memory for missing children. J APPL RES MEM COGN 1(4):235-241. https://doi.org/ 10.1016/j.jarmac.2012.08.001

Taylor J, Boisvert D, Sims B, Garver C (2013) An examination of gender and age in print media accounts of child abductions. Crim Justice Stud 26(2):151-167. https://doi.org/10.1080/1478601x.2012. 724683

U.S. Department of Justice (2015) Guidelines for issuing AMBER alerts. Retrieved from: http://www.amberalert.gov/guidelines.htm

White D, Kemp RI, Jenkins R, Matheson M, Burton AM (2014) Passport officers' errors in face matching. PLOSone 9(8):1-6. https://doi.org/ 10.1371/journal.pone. 0103510

Yarmey AD, Jacob J, Porter A (2002) Person recall in field settings. J Appl Soc Psychol 32(11):2354-2367. https://doi.org/10.1111/j. 1559-1816.2002.tb01866.x

Publisher's Note Springer Nature remains neutral with regard to jurisdictional claims in published maps and institutional affiliations. 